\title{
Medical Diagnosing by Chemical Analytical Tools
}

DOI: $10.1134 / \mathrm{S} 1061934810110018$

It is known that the results of routine clinical analyses of blood or urine are important indexes for detecting diseases. The continuous and rather wide investigations result in the discovery of new disease markers, which forces analysts to develop methods for their detection and quantitative determination. In addition to blood and urine, which remain the main objects of analysis in this field, it has become necessary to analyze sweat, saliva, hair, nail cuts, exhaled air, etc. The analytes are individual chemical elements, but more often low-molecular organic substances of biochemical origin, and now even high-molecular natural compounds. This predetermines the necessity for using various methods of analysis, better in computerized or semiautomated versions, because the scope of investigations is usually rather great. We suppose that systems of the "electronic nose" and "electronic tongue" type will find wide application.

In the recent monograph [1], the problem of using analytical methods in medical diagnostics was considered from the viewpoint of analysts. Here, I would like to note some solutions of the past few years.

A method was proposed for the determination of biomarkers of brain injuries in blood. The US army has purchased the development of a hand-operated instrument for such analysis by the SFC Fluidics Corporation, having signed a contract for 5 million dollars with the Company. The tests of the instrument are planned for 2013 [2]. Using sensors based on polymer nanoparticles, one can recognize cancer cells against healthy ones [3].
The researchers of the Division of Analytical Chemistry of Moscow State University together with their colleagues from the Institute of Pulmonology of the Russian Academy of Medical Sciences are working on the development of methods for the detection of pulmonary diseases by the composition of exhaled air. Thus, a change in the concentration of hydrogen peroxide in this air is indicative of asthma, tuberculosis, and other diseases; a biosensor was developed for the determination of the concentration of hydrogen peroxide. Changes in the concentrations of volatile organic compounds have also been studied.

In connection with the scandal related to the intoxication of children in China by cyanotriamide present in infants' milk (cyanotriamide attacks the kidney), it was necessary to develop rapid methods for the detection and determination of this compound not only in food stuffs and medicines but also in biological materials.

\section{REFERENCES}

1. Khimicheskii analiz $v$ meditsinskoi diagnostike (Chemical Analysis in Medical Diagnostics), (Ser.: Problemy analiticheskoi khimii (Problems of Analytical Chemistry), vol. 12), Budnikov, G.K., Ed., Moscow: Nauka, 2010.

2. Chem. Eng. News, 2009, October 19, p. 41.

3. Chem. Eng. News, 2009, July 13, p. 17.

Yu. A. Zolotov 